\title{
O ABANDONO SOCIAI, DA INFÂNCIA E ADOLESCÊNCIA NA ÁTICA DOS COORDENADORES DE INSTITUIÇÕES DE ASSISTÊNCIA A CRIANÇAS E ADOLESCENTES EM SITUAÇÃO DE RUA NA CIDADE DE GOIÂNIA
}

\author{
THE MEANING OF THE SOCIAL ABANDONMENT OF CHILDREN \\ AND ADOLESCENTS FROM THE POINT OF VIEW OF \\ COORDINATORS OF SHELTERS FOR STREET CHILDREN AND \\ ADOLESCENTS IN GOIANIA
}

\author{
Michella Florência Barbosa Câmara ${ }^{1}$ \\ Marcelo Medeiros ${ }^{2}$ \\ Maria das Graças Carvalho Ferriani ${ }^{3}$ \\ Romeu Gomes ${ }^{4}$
}

CÂMARA, M. F. B.; MEDEIROS, M.; FERRIANI, M. d. G. C.; GOMES, R. O abandono social da infancia e adolescência na Ética dos coordenadores de instituições de assistência a crianças e adolescentes em situação de rua na cidade de Goiania. Rev. Bras. Cresc. Desenv. Hum., São Paulo, 12 (1), 2002.

Resumo: Este estudo analisou as percepções de coordenadores de instituições que prestam assistência a crianças e adolescentes em situação de rua sobre a infância e a adolescência nesta condição. É um estudo qualitativo, realizado no Município de Goiania. Os dados foram obtidas em entrevistas semi-estruturadas com os coordenadores de programas e analisados na modalidade temática da análise de conteúdo. Os alores sociais, envolvidos nesta realidade, percebem o abandono social da infancia como resultado de uma desestruturação político-social de nosso país. Acreditam que o cumprimento real do Estatuto da Criança e do Adolescente será possível quando tivermos a garantia dos direitos sociais estipulados em nossa constituição.

Palavras-chave: crianças de rua; política social; enfermagem em saúde pública; saúde pública.

\section{INTRODUÇÃO}

Crianças e adolescentes em abandono e vivendo em situação de risco social representam uma realidade de nossa sociedade, que deve ser analisada sob os olhos de nossa conjuntura social, levando em consideração a historicidade desta questão, movida por acontecimentos sociais, interesses políticos e econômicos. Representam a concretização e legitimação do abandono social da infância; poderíamos dizer, do descompromisso do Estado para com a família e para o papel social que esta possui.

1 Enfermeira, aluna de Pós-Gradua^São Nivel Mestrado do Departamento de Enfermagem Materno-Infantil da Escola de Enfermagem de Ribeirão Preto da Universidade de São Paulo. (michella.camara bol.com.br)

2 Doutor em Enfermagem, Professor Adjunto da Faculdade de Enfermagem da Universidade Federal de Goiás. Rua 227, Qd 68 s/n, FEN-UFG; St. Leste Universitário - Cep: 74605-080 - Goiània - GO. (marcelo fen.ufg.br)

3 Doutora em Enfennagem, Professora Titular do Departamento de Entermagem Materno-infantil e Saúde Pública da Escola de Enfermagem de Ribeirão Preto da Universidade de São Paulo. Endereço: Av.Bandeirantes, 3900; Monte Alegre - Cep: $14040-902$ - Ribeirão Preto - s^P. (caroline glete.eerp.usp.br)

4 Doutor em Saúde Pública, Pesquisador Associado do instituto Fernandes Figueira/Fundação Oswaldo Cruz: Av. Rui Barbosa, 716; Flamengo - Cep: 22250-020 - Rio de Janeiro - ^RJ. (romeu iff.fiocruz.br). 
"Meninos e meninas de rua" devem ser percebidos como quaisquer outras crianças e adolescentes; porém, a necessidade - de cunho material, de afeto ou proteção - impulsiona-as para a rua. São provenientes de famílias trabalhadoras expropriadas com uma história de vida marcada pela luta constante pela sobrevivência (MINAYO, 1993).

A denominação "crianças e adolescentes em situação de rua” é, dentre os inúmeros termos encontrado a que melhor expressa a real condição destes indivíduos, que não pertencem à rua, mas encontram nessa uma circunstância de vida. GRACIANI (1997) compreende este grupo como oprimidos e relegados pelo sistema social e não como marginais sociais, sendo que a classificação "de" e "na” rua expressa uma categoria social que tem a rua como um território de vida e de trabalho resultante de um processo social de dominação, exploração e de exclusão.

A história do abandono da infância e adolescência insere-se em uma trama social do mundo contemporâneo, marcado por um modo de produção excludente, de concentração de renda e, conseqüentemente, de poder. Permeado por inúmeras crises e remodelado em inúmeras formas, atualmente tem como modelo o neoliberalismo de mercado, que re-introduz o liberalismo clássico, elitista.

Com isto, há o agravamento paulatino da distribuição desigual de riqueza e o cresciinento das massas desfavorecidas, com altos índices de desemprego e de miserabilidade, atingindo diretamente e desestruturando a instituição de maior responsabilidade pela inserção do indivíduo na sociedade: a família.

Neste contexto, o Estado é um meio de garantia formal da cidadania, dos direitos à vida, à igualdade, à proteção, à educação, entre outros, com fins de mediar uma relação justa entre detentores/concentradores de riquezas e compradores da força de trabalho e a grande massa. Temos, contudo, em nossa realidade, o Estado como um grande meio reafirrnador das desigualdades estruturais de nosso país, onde as políticas sociais são entendidas como concessões do Estado, e não como direito.

Nesta ética, a política de um Estado Mínimo não intervencionista trabalha em prol da lógica de mercado que, por sua vez, dita a ordem social do mundo, conforme seus interesses próprios. Nesta conjuntura, ocorre o descaso e o descompromisso do Estado com as questões de ordem social, expondo aqueles que possuem menores condições de enfrentá-las às conseqüências dessa estrutura social. Isto pode ser observado ao analisarmos a situação dos menos favorecidos economicamente e, mais ainda, face à situação das mulheres, negros, idosos, crianças e adolescentes.

As políticas de atenção a crianças e adolescentes em situação de rua surgem da ineficiência e ineficácia do Estado em suas políticas econômicas, agrárias, habitacionais, educacionais e de saúde. As instituições de amparo a crianças e adolescentes em situação de rua não seriam necessárias caso houvessem políticas sociais eficazes, que dessem conta das causas geradoras desta realidade.

Ao fazer uma análise das políticas sociais destinadas a esta parcela da sociedade, SOUZA NETO (1993) afirma que "a história brasileira é carregada da privação dos direitos sociais à infância e à adolescência Isso significa que a ausência de políticas sociais bem estabelecidas já constitui um corolário da abertura para uma 'política de genocídio’, presente em toda a história brasileira da criança e do adolescente” (p. 79).

Desta forma, instalam-se políticas assistencialistas que visam resolver um determinado problema sem se preocupar com as causas e suas possíveis conseqüências. Estratégias voltadas à garantia das necessidades sociais de emprego, com remuneração justa, educação, saúde, moradia e lazer com qualidade, teriam maiores chances de quebrar a cadeia geradora do fenômeno social de crianças e adolescentes em situação de rua. No entanto, as políticas de atenção à criança e ao adolescente em situação de rua em nosso país são marcadas por uma trajetória de enorme descompasso político entre discurso legal, ideologias e práticas, ações governamentais e não governamentais desuniformes, com as mais diversas concepções sobre a questão do abandono social da infância (SOUZA NETO, 1993; GREGORI \& SILVA, 2000).

Refletindo sobre os agravos individuais e sociais vividos por crianças e adolescentes em situação de rua, observamos uma problemática de saúde pública, no entanto ainda pouco entendida como tal, haja vista o pouco envolvimento do setor saúde junto a estas questões. Na realidade, conforme aponta MEDEIROS (1999), existe um desvinculamento dos profissionais da saúde com a questão do abandono social da infância e adolescência. Este autor, referindo-se à Enfermagem, observou a baixa produção científica abordando a temática para o período de 1982 a 1998 representando, assim, o pouco envolvimento com estudos e ações voltados a este grupo por esta área específica. Nesse sentido, entendemos que a desconstrução desta concepção de desvinculamento entre as práticas de saúde pública e o abandono social da infância passa pela compreensão de que, devido à característica multidimensional implíci- 
ta neste fenômeno, requer práticas interdisciplinares e, para tal, torna-se necessário um debate amplo com diversos segmentos da sociedade, incluindo o setor saúde.

A eficácia de qualquer ação depende do nível de conhecimento que possuímos da realidade, na qual se insere o objeto a que se destina a intervenção. Nesse sentido, inúmeros estudos se propõem a compreender a questão do abandono social da infância e adolescência em nosso país oferecendo uma significativa contribuição na construção do conhecimento deste fenômeno social. No entanto, há necessidade de conhecermos as especificidades locais para que as propostas de ações voltadas a este grupo tenham um melhor direcionamento e, assim, tenham maiores possibilidades de sucesso (MINAYO, 1993). Desta forma, propomo-nos estudar a realidade goianiense, visto ser este um fenômeno atual nesta comunidade, unindo-se ao fato de termos nesta localidade um déficit de conhecimentos concretos sobre a realidade das crianças e adolescentes em situação de rua.

Diante disto, propusemos neste estudo analisar as percepções sobre infância e adolescência em situação de rua sob a ética dos coordenadores de programas voltados a este grupo em Instituições governamentais e não governamentais, com vistas a oferecer subsídios para a construção de propostas de atendimento, no âmbito da saúde pública, às crianças e adolescentes em situação de rua da cidade de Goiania.

\section{CAMINHO METODOLÓGICO}

Este estudo foi construído dentro de uma abordagem da pesquisa social em saúde (MINAYO, 1994) e realizado no Município de Goiânia, capital que enfrenta um acelerado crescimento demográfico e, consequentemente, um alargamento de suas delimitações periféricas. Goiânia é uma localidade de importância no processo migratório de uma enorme massa da população rural em busca de outras formas de subsistência, sendo também relatado, de forma mais recente, a migração para esta região de famílias provenientes de grandes metrópoles, principalmente do sudeste na busca de melhores chances de sobrevivência. Tem no comércio sua fonte econômica principal, sendo a agricultura e pecuária também ramos fortes. No entanto, estes setores atravessam um período de crise evidenciado por um número crescente de desemprego e subemprego, o que não foge à regra de nosso país.

MEDEIROS (1999, p. 63), estudando as representações sociais da experiência de vida de meninos em situação de rua no Município de Goiâ nia, remete-nos ao fato de que é crescente o número desta população nesta região. Considerando a inexistência de dados oficiais que permitam quantificar a presença de meninos(as) nas ruas de Goiânia, com base em dados extraoficiais o autor relata existir, na época de seu estudo, cerca de 80 crianças nesta situação. Isto demonstra a necessidade de investigações amplas no sentido de se conhecer esta realidade através de pesquisas específicas para tal, uma vez que o crescimento populacional da capital, nos últimos cinco anos, tem sido bastante acentuado.

Este estudo foi realizado junto a instituições que propõem oferecer suporte e/ou trabalhar junto a esta população, sejam elas de caráter governamental ou não governamental. Isto significa que procuramos por aquelas que desenvolvem ações assistenciais direcionadas à recuperação, prevenção e suporte aos meninos e meninas que saem das ruas em busca de abrigo ou de uma forma de retornar às suas casas e famílias. Não centramos a atenção, neste momento, naquelas instituições ligadas ao aparato jurídico legal.

Utilizamos como instrumento para a coleta de dados a entrevista semi-estruturada gravada em fita cassete, realizada mediante o conhecimento, pelo entrevistado, de nossos objetivos e respectiva concordância e assinatura de termo de consentimento livre e esclarecido, segundo portaria do Conselho Nacional de Saúde (Resolução 196/ 96). Utilizamos também a observação e registros em diário de campo.

Para a análise de nossos dados utilizamos a Análise de Conteúdo - Modalidade Temática proposta por BARDIN (1979). Os dados foram interpretados após leituras sistematizadas e agrupados mediante o surgimento de estruturas relevantes e, destas, estabelecemos núcleos de sentido, construídos a partir do grupo social estudado.

Na etapa seguinte, e partindo da identificação dos núcleos de sentido, confrontamos as nossas observações com a construção teóricocientífica e com as falas dos coordenadores dos programas procedendo assim à análise dos resultados, através de dois aspectos de análise: “as percepções” e “a violência do não ter”.

\section{RESULTADOS E DISCUSSÃ O}

\section{O espaço da pesquisa}

Durante a realização de nosso estudo, as políticas municipais voltadas às crianças e aos adolescentes em situação de rua concentravam-se na Fundação Municipal de Desenvolvimento Comunitário (FIJMDEC), estando aí vinculadas a um 
projeto de grande extensão intitulado Cidadão 2000 e, dentro deste projeto, mais especificamente, encontravam-se sob a responsabilidade da Divisão de Proteção e Defesa da Infância e Adolescente (DPDIA).

Ligados a esta última instância executora, haviam programas voltados para crianças e adolescentes em situação de risco social, onde foram observadas as seguintes instituições e projetos em andamento: SOS - Crianças, Casa de Passagem, Casas Lares, Projeto Educadores de Rua, além de convênios com instituições para desintoxicação.

No período de coleta de dados havia, em Goiânia, oito instituições voltadas especificamente para a atenção a crianças e adolescentes en situação de rua, sendo duas casas de passagem, uma masculina e outra feminina, ambas instituições governamentais. Existiam, ainda, cinco casas lares o que o Estatuto da Criança e do Adolescente (ECA, 1990) caracteriza como instituições abrigos -, sendo três masculinas e duas femininas, todas não governamentais (ONG). No entanto, recebiam alguma ajuda financeira ou de pessoal através da Prefeitura Municipal. Observamos ainda a presença relevante de educadores de rua ligados às casas de passagem, exercendo suas funções diretamente na rua ou na própria casa.

\section{Os coordenadores}

Foram atores sociais de nossa pesquisa os coordenadores ligados às instituições de atenção a crianças e adolescentes em situação de rua, sendo realizadas nove entrevistas, duas em casas de passagem, quatro em casas lares, uma com responsáveis pela equipe de educadores de rua, uma em instituição de desintoxicação e uma com responsáveis diretos pela DPDIA.

Quanto à escolaridade, sete dos nove entrevistados possuíam terceiro grau completo (pedagogos ou assistentes sociais) e apenas dois tinham o nível médio. O sexo feminino foi preponderante e a idade, em média, foi de 34 anos. Dois coordenadores exerciam trabalho voluntário, sendo os demais contratados, com vínculo empregatício formal com o Município. O tempo de trabalho na instituição estava entre um ano e meio a sete anos, e o tempo de trabalho com esta população, entre um ano e meio e 20 anos.

A carga horária de trabalho, mínima, encontrada foi de oito horas diárias, sendo que nas casas lares, os coordenadores faziam uma jornada de trabalho significantemente maior, pois lá ressidiam, o que não ocorreu em apenas uma das Casas Lares.

\section{As percepções}

Após esta breve descrição do cenário onde se desenvolveram as ações políticas de atenção às crianças e aos adolescentes em situação de rua no Município de Goiânia, apresentaremos a discussão sobre o discurso de nossos atores sociais com base nos aspectos de análise anteriormente citados.

\subsection{A violência do não ter}

Os atores sociais tecem considerações unânimes sobre quem são as crianças e o adolescente em situação de rua. Direta ou indiretamente, todos os coordenadores pesquisados caracterizaram a criança e o adolescente em abandono social como aqueles que, nesta fase da vida, fazem da rua uma forma de sobrevivência, e são compelidos para esta realidade por algum tipo de violência, seja esta estrutural ou familiar, e continuam a sofrer violências de inúmeras naturezas no ambiente da rua.

Conceitualmente MINAYO (1994) aponta que a violência pode ser dividida em estrutural, de resistência e de delinqüência. A primeira, consiste naquela ligada às desigualdades sociais que levam à opressão e à discriminação de grupos vulneráveis. A violência de resistência constitui-se das diferentes formas de resposta dos grupos, classes e indivíduos oprimidos. A violência de delinqüência é caracterizada como aquela que se revela nas ações fora da lei socialmente reconhecida.

Para os atores sociais, várias são as formas de violência vividas por esta população:

"Começam a sofrer violência nafamilia. não é só espancamento não, violência da fome, violência do não ter... eu vejo como uma criança segregada dos direitos que deveriam ter, quer por conta da família, quer por conta do governo, quer por culpa da sociedade". (Coordenador 03)

As falas dos atores sociais vêm ao encontro das colocações de pesquisadores desta temática onde se afirma, mais uma vez, o fenômeno crianças e adolescentes em situação de rua como o topo máximo de uma exclusão social, realizada por fatores históricos, econômicos e políticos de nossa sociedade, sendo a violência, sofrida por crianças e adolescentes, uma configuração concreta desta exclusão social.

Para DREXEL \& IANNONE (1991), a violência contra a criança e o adolescente é um falo comum em nossa sociedade. O Brasil é o quarto colocado mundial em violência familiar contra acriança. Para estes mesmos autores, aviolência não é só familiar, também provem do Estado e da sociedade civil, sendo que as políticas desenvolvidas no Brasil com a criança e o adolescente são falhas em todos os sentidos, levando-os a um es- 
tado de miséria e desproteção que os empurra cada vez mais para condições subumanas, com a violação de seus direitos fundamentais.

"Necessidade, tanto material quanto afetiva, é produto de uma situação estrutural de nosso país. A má distribuição de renda, o desemprego, falta de investimento na educação, falta de estrutura para manter as famílias”. (Coordenador 02)

Nos estudos de MEDEIROS (1999, p. 1 14), sobre as representações sociais da rua para meninos do Município de Goiania, a análise da categoria empírica “A gente Não Tem “ é apresentada como um dos significados da rua para crianças e adolescentes envolvidos napesquisa. Para estas crianças, o "não ter” representa, da mesma forma que para nossos coordenadores, a falta da família, de condições mínimas de sobrevivência, a falta de futuro.

Verificamos inúmeros fragmentos nas falas dos coordenadores que reafirmam o encontro das percepções destes sobre crianças e adolescentes em situação de rua, com a construção teórica existente da temática:

"Um adolescente totalmente violado em seus direitos, vítima de uma sociedade que não tem uma ética, e não tem uma conduta moral, não tem uma distribuição de renda, não tem um salário digno, e por isso as famílias entram em crise. O salário do pai que não existe, a falta da mãe, a falta da constituição familiar, a falta de escola, a falta de uma política de assistência adequada, a falta de distribuição de renda do país, a falta de reforma agrária... vítimas de um sistema”. (Coordenador 08)

Para os atores, a violência sofrida por estas crianças assume várias formas passando pela violência física, violência do abandono, violência sexual e violência emocional, sendo que todas possuem como pano de fundo uma violência de abandono e exclusão social, vivida pelas famílias destas crianças e adolescentes.

CRUZ NETO, SOUZA \& ASSIS (1993) apontam para o fato de que "ao lidar com famílias de crianças que buscam na rua sua sobrevivência, a desconstrução do modelo familiar tradicional e o surgimento de outro modelo em que a escassez material, as precárias condições de moradia, a pouca qualificação profissional, baixa escolaridade, enfim, toda uma sorte de carências impõem limites e impedem a ultrapassagem para uma vida melhor” (p. 65; p. 86).
Como síntese das características encontra das para famílias em situação de rua ou com membros em situação de rua pelos pesquisadores acima citados, temos uma história de luta e miserabilidacle; sofrimento direto ou indireto dos efeitos dos processos migratórios vividos em nosso país, pertencem em grande maioria a uma etnia negra ou a descendentes; as famílias em geral, possuem em média uma alta densidade de pessoas por domicílio; e quase sempre são chefiadas por mulheres. O uso de substâncias psicotrópicas, incluindo o álcool, faz-se presente muito comumente nos conflitos familiares que são quase uma constante, sendo que para estes autores, a dificuldade de sobrevivência acaba também limitando as relações afetivas (CRUZ NETO, SOUZ A \& ASSIS, 1993). Muitos coordenadores forneceram algumas características desta população:

“A maioria não são de Goiânia, são do entorno... cidades vizinhas...". (Coordenador 02)

“Não têm auto-estima e não têm a menor perspectiva de vida...”. (Coordenador 03)

“99\% deles começam no subemprego, pai alcoólatra, mãe alcoólatra”. (Coordenador 03)

Tais características se assemelham às apresentadas por DREXEL \& IANNONE (1991) tais como, "não pensam no futuro próximo ou distante, são imediatistas; organizam-se em grupos e andam em bandos; deixam a casa pressionados pela miséria e/ou violência; provêm de famílias migrantes; muitos não sabem o próprio nome; não valorizam a propriedade alheia; têm dificuldade de se envolver emocionalmente, com medo do abandono".

A intersecção das percepções de nossos atores sociais com o discurso teórico não ocorre ao acaso, sendo resultado de um avanço de movimentos sociais em prol da garantia dos direitos humanos onde, estes coordenadores de alguma forma estão envolvidos. Em uma fala podemos observar este fato:

“A cidadão 2000 não surgiu por acaso, surgiu através de lutas realizadas por uma parcela da sociedade que já lutavam em favor das crianças e adolescentes em Goiânia... vem legitimar o ECA". (Coordenador 08)

Somente com uma visão global deste fenômeno de exclusão social, vivida por crianças e 
adolescentes, estes atores sociais terão maiores chances de atuarem de forma efetiva nesta realidade.

\section{CONSIDERAÇÕES FINAIS}

Ao iniciarmos este estudo, tivemos a intenção de compreender alguns aspectos da realidade do Município de Goiania no que se refere à assistência a crianças e adolescentes em situação de rua. Para tanto, buscamos nas percepções dos coordenadores de instituições que respondem às políticas destinadas à minimização dos danos causados pelo abandono social da infância e adolescência elementos para compreendermos um pouco sobre esta realidade. Entendemos ser este um primeiro passo no sentido de buscar subsídios para a elaboração de propostas alternativas que possam intervir nas possíveis causas desta situação de abandono social, ainda que no universo da área da saúde.

Um dos aspectos que foi possível constatarmos neste estudo foi que as percepções dos atores sociais envolvidos nesta realidade política e institucional demonstram grande ligação com os dados teóricos encontrados. Fazem uma representação do abandono social da infância e juventude como resultado de uma desestruturação políticosocial do país que deixa suas marcas no abalo das bases familiares, provocando desagregações no núcleo familiar.

O grande parâmetro para as ações mediadas por coordenadores destas instituições é o cumprimento do Estatuto da Criança e do Adolescente (ECA, 1990); no entanto, os mesmos reconhecem inúmeras limitações, principalmente quando caracterizam suas atividades como "terciárias ou curativas", voltadas para a minimização de danos causados pelo desamparo social e desrespeito à dignidade humana, em que sobrevivem estas crianças e adolescentes, sendo que possuem poucas possibilidades de uma atuação voltada para questões preventivas.
O cumprimento real do ECA-90 será uma realidade quando tivermos em nosso país a garantia dos direitos sociais estipulados em nossa constituição, com observância ao respeito aos direitos humanos, o que só será possível mediante a valorização e efetivação de políticas sociais básicas como a garantia de educação, saúde, moradia em condições dignas, emprego, entre inúmeras outras políticas que valorizem o ser humano em integralidade e sem discriminações.

Neste contexto, as políticas de atenção a crianças e adolescentes em situação de abandono social em nossa realidade são aparatos que não vizam sanar o problema, e sim, minimizar a questão. Não estamos aqui questionando a importância destas instituições. Ao contrário, acreditamos que, enquanto frutos de uma luta social, representam a única chance de resgate de cidadania que estas crianças e adolescentes possuem, além de terem uma responsabilidade social de reflexão e compreensão do fenômeno e luta para a garantia de políticas realmente eficazes, não apenas paliativas, mas que dêem conta da diminuição ou erradicação da exclusão social da infância.

Desta forma, sentimos a necessidade de, cada vez mais, lutarmos para o aperfeiçoamento e garantia de qualidade dos servicos prestados por estas entidades. Esta pesquisa levantou alguns pontos obscuros que requerem a necessidade de outros estudos, sendo também útil para nos demonstrar a necessidade de um maior compromisso dos profissionais da área de saúde para esta realidade social que deve ser vista como um fenômeno multidimensional e, portanto, requer uma atuação interdisciplinar.

\section{AGRADECIMENTO}

O desenvolvimento deste estudo contou com o apoio do Núcleo de Estudos e Pesquisas em Saúde Integral (NEPSI) da Faculdade de Enfermagem da Universidade Federal de Goiás (FEN-UFG).

\begin{abstract}
This study aimed to analyze the perceptions regarding street children and adolescente of coordinators of shelters for this specific group. It was a qualitativo research developed in the city of Goiania, Brazil. Data was obtained through semi-structured interviews and analyzed through lhe thematic modality of content analysis. The social actors involved in this reality view lhe social abandonment of childhood as a direct consequence of the Brazilian political and social context. They believe that the enforcement of the Child and Adolescent Statute (ECA) will be possible only when the social rights stipulated in the Brazilian Constitution are warranted.
\end{abstract}

Key-words: homeless children and youths; public policy, public health nursing; public health 


\section{REFERÊNCIAS BIBLIOGRÁFICAS}

BARDIN, L. Análise de conteúdo. Lisboa: Edições 70, 1979.

BRASIL. Estatuto da Criança e do Adolescente. Lei 8069/90. São Paulo: Atlas, 1990.

CRUZ NETO, O.; SOUZA, E.R.; ASSIS, S.G. Rede familiar: a reconstrução pela desconstrução. In: MINAYO, M. C. d. S. O limite da exclusão social: meninos e meninas de rua no Brasil. São Paulo/Rio de Janeiro: Hucitec/ Abrasco, 1993. Capítulo 3, p.65-96.

DREXEL, J.; IANNONE, L. R. Crianças e miséria: vida ou morte? $6^{a}$ ed. São Paulo: Editora Moderna, 1991. (Coleção Polêmica)

GRACIANI, M. S. S. Pedagogia social da rua. análise e sistematização de uma experiência vivida. São Paulo: Cortez, 1997.
GREGORI, M. F.; SILVA, C. A. Meninos de rua e instituições: tramas, disputas e desmanche. São Paulo: Contexto, 2000.

MEDEIROS, M. Olhando a lua pelo mundo da rua: representações sociais da experiência de vida de meninos em situação de rua. Ribeirão Preto, 1999. [Tese de Doutorado - Escola de Enfermagem de Ribeirão Preto da Universidade de São Paulo].

MINAYO, M. C. S. (Org.). O limite da exclusão social: meninos e meninas e rua no Brasil. São Paulo/Rio de Janeiro: Hucitec-Abrasco, 1993.

MINAYO, M. C. S. (Org.). O desafio do conhecimento: pesquisa qualitativa em saúde. São Paulo/Rio de Janeiro: Hucitec-Abrasco, 1994.

SOUZA NETO, J.C. De menor a cidadão. filantropia, genocídio, políticas assistenciais. São Paulo: Nuestra América, 1993.

Recebido em 29/09/2001 Modificado em 10/02/2002 Aprovado em 19/02/2002 